point. Moreover, he correctly concludes that near-patient testing has a number of potential benefits beyond patient satisfaction, although the full potential of its integration and implementation has not been exploited, while he specifically calls for rigorous evaluations to determine improvements in harder outcomes and cost-effectiveness. Yet, we noticed that he mainly focused on near-patient testing opportunities in the field of cardiovascular medicine. A recent review, not included in this editorial, showed unsatisfactory results of near-patient tests for monitoring patients with diabetes, with hyperlipidaemia, or requiring anticoagulant therapy. ${ }^{2}$ But the same research group also showed that patients managed with near-patient tests had similar or superior medication adherence: that is an important finding in patients who often use multiple medications. ${ }^{3}$

The potential of near-patient testing for acute conditions in general practice is largely neglected in the editorial. Yet, in our opinion this is where near-patient testing can have the most effect. GPs preferably want to decide on management within the 10-minute-consultation for an acute condition. Recently it was shown that using a clinical decision rule combined with a point of care D-dimer reduces the need for referral to secondary care of patients with clinically suspected deep venous thrombosis (DVT) by almost $50 \%$ and is associated with a low risk for subsequent venous thromboembolic events. Point of care D-dimer tests can therefore contribute important information and guide patient management, notably in low risk DVT patients. ${ }^{4,5} \mathrm{~A}$ second example of a near-patient test with immediate consequences for management is the use of point of care C-reactive protein (CRP) testing in lower respiratory tract infections. A recent trial showed a dramatic decrease in antibiotic prescriptions when GPs used CRP testing to guide antibiotic management. ${ }^{6}$ Both biomarkers now have a solid evidencebase of their use, with multiple studies showing robustness, effectiveness on hard outcomes, and cost-effectiveness. So contrary to what Khunti claims, we contend that there has been quite some progress in terms of rigorous evaluations of near-patient testing initiatives in primary care in the past decennium, especially when focusing at their use in acute conditions. And this is exactly where nearpatient tests will benefit GPs and patients most.

Jochen WL Cals, Post-Doctoral Researcher and GP Trainee, CAPHRI School for Public Health and Primary Care, Maastricht University, The Netherlands. E-mail: j.cals@hag.unimaas.nl

\section{Geert-Jan Geersing,}

GP and Researcher, Julius Center for Health Sciences and Primary Care, University Medical Center Utrecht, Netherlands.

\section{REFERENCES}

1. Khunti K. Near-patient testing in primary care. $\mathrm{Br} \mathrm{J}$ Gen Pract 2010; 60(572): 157-158.

2. Gialamas A, St John A, Laurence CO, Bubner TK. Point-of-care testing for patients with diabetes, hyperlipidaemia or coagulation disorders in the general practice setting: a systematic review. Fam Pract 2010; 27(1): 17-24.

3. Gialamas A, Yelland LN, Ryan P, et al. Does point-ofcare testing lead to the same or better adherence to medication? A randomised controlled trial: the PoCT in General Practice Trial. Med J Aust 2009; 191(9): 487-491.

4. Buller HR, Ten Cate-Hoek AJ, Hoes AW, et al. Safely ruling out deep venous thrombosis in primary care. Ann Intern Med 2009; 150(4): 229-235.

5. Geersing GJ, Janssen KJ, Oudega R, et al. Excluding venous thromboembolism using point of care Ddimer tests in outpatients: a diagnostic meta-analysis. BMJ 2009; 339: b2990.

6. Cals JW, Butler CC, Hopstaken RM, et al. Effect of point of care testing for $\mathrm{C}$ reactive protein and training in communication skills on antibiotic use in lower respiratory tract infections: cluster randomise trial. BMJ 2009; 338: b1374.

DOI: 10.3399/bjgp10X502218

\section{GPs and minor ailments}

In recent years there have been a number of reports of GPs being troubled by patients with minor ailments, while at the same time concerns have been expressed about the iceberg of unreported illness in the community.

When the perceptions of people are taken into account, one study showed that $26 \%$ had symptoms that to them were serious, but did not seek medical advice for. In contrast $11 \%$ had symptoms that they did not think were serious but that were referred to a GP. The iceberg of significant symptoms in the community was therefore more than twice the size of so called trivial complaints.

This begs the question of 'trivial to whom?' GPs are extensively trained and paid to distinguish minor ailments from those that may be more serious. It is therefore disappointing that prominent members of the profession have recently promoted the view that doctors are overwhelmed with minor ailments, with the implication that patients should seek advice elsewhere and spend more on over-the-counter medicines.

\section{David Hannay,}

Kirkdale, Carsluith, Wigtownshire, DG8 7EA.

E-mail: drhannay@gmail.com

\section{REFERENCE}

1. Hannay DR. The Symptom Iceberg. London: Routledge \& Kegan Paul Ltd., 1979.

DOI: 10.3399/bjgp10X509649

\section{GP training 'schemes'}

I would like to bring to mind an alternative viewpoint to that brought up in the May Focus regarding length of GP training 'schemes'. ' Length of training for a GP is compared unfavourably with those elsewhere, on the basis that it involves only 3 years ( 2 in hospital and 1 in 'registrar' posts) compared to longer, far more defined schemes in other specialties. I am not sure that this very short standard GP training scheme is in fact the standard, and I am not sure the 'standard' differs so very much really from that in other specialties in Britain.

GP training has always been more flexible than other speciality schemes, allowing trainees far more opportunity for more mature self-evaluation, self-directed learning, and practical experience organisation. It may be possible to satisfy the requirements of the 
nMRCGP/JCPTGP exam by demonstrating only 2 years in hospital posts, plus 1 year in GP-land, plus passing the exam, BUT many trainees in practice recognise that this is a basic core requirement, not a maximum requirement, and indeed, so do many potential

GP-employers.

Until very recently, secondary care specialists (in other words, all specialists other than GPs) were appointed by people outside of their speciality, or even outside of medicine, but new GPs were appointed by other, senior, GPs, wellversed in their same speciality (except of course in ancient times, when anyone who failed to successfully complete medical or surgical training could set up as a GP, but even then might not do so well at it!). Still, even now, the majority of new GPs are employed by more senior fellow professionals, who supervise them to a varying extent (according to need) for varying periods of time. Most new partners start their partnership life as junior partners. But back to training length. I am not sure I know any of my contemporaries who went from a minimum length training scheme into a senior GP job!

I myself did two posts as house doctor of very good experience level I believe, followed by an additional 6 months in A\&E, before entering a '3-year' scheme; following that I took additional posts in general medicine, A\&E, a full year in paediatrics with O\&G, 22 months in joint A\&E with medicine, rehab, and a little surgery at senior hospital doctor level, and then 18 months locum GP work. I then joined a (training) practice part-time while still doing locum work for another year, before becoming full-time in a rural training practice with responsibility for covering A\&E and acute care, later moving to include in my portfolio posts, as representative on the LMC and RMC. If I were looking for a new partner for our practice now, I would be looking for well-rounded and additional experience beyond the minimum required to ENTER for the nMRCGP exam. Of course, now the exam includes modules in audit and videoing, it is often found that trainees cannot complete all the modules during the 'minimum-duration' scheme, and very many do additional posts while completing the exams. Taking into account the recent changes that mean all medical graduates now do 2 years at pre-registration level, I think this means that many will complete GP qualification with experience and study similar to that of hospital specialties, if not more.

Trainees are putting in a lot of extra work towards examinations in their own time, and gaining experience outside of approved scheme posts, because they feel it is needed (and so do their potential employers). With this situation driving the quality, and indeed the (unmeasured) length of an actual GP's training, I feel the preservation of flexibility in the system is a huge bonus: it encourages maturity in self-directed learning and evaluation (at least when properly encouraged) that fits trainees well for the continual educational development they will face in real general practice.

An argument used all along against lengthening GP training is the fact that hospitals want to hijack the extra compulsory time to get more cheap service provision work out of trainees, while I, and many others, remain convinced that this is still a significant risk.

\section{David Church,}

GP (passed Welsh trainer modules),

Machynlleth.

E-mail: David.Church@gp-w96014.wales.nhs.uk

\section{REFERENCE}

1. Jones R. Questions for the GP curriculum. Br J Gen Pract 2010: 60(574): 314.

DOI: 10.3399/bjgp10X502236

\section{Frontline innovation is free but not easy}

Delaney's final conclusion on his editorial on cutting-edge information technology struck a chord with my work over the last 8 years. He suggested that in the future such IT will have to be freely available and with universal standards. ${ }^{1}$ So far I have received no monetary grants for my work and have made my ideas and programs freely available to other like-minded GPs.

My first frontline idea incorporated the reasons for drug use on the repeat prescription screen of the IT system. This modernises the delivery of medicines and is described in detail on the website, ${ }^{2}$ it is called clinical indications. The second idea (shared with my specialist practice nurse) was the development of a smoking calculator to calculate a pack-year number, that is, overall total smoking exposure for individual patients. This can be difficult to do due to changing smoking patterns and remembering the basic pack-year calculation. This calculator has been given freely to all on the web ${ }^{3}$ and there is an embedded version within general practice IT systems. This is available from Informatica Systems (Contract Plus module) and has in-built disease associations. Our names are on our calculator for standardisation purposes and this may be the first working frontline team to have their names actually shown within the modern general practice IT system! My most recent general practice program is a children's dose calculator for using liquid dexamethasone in croup. The latter is available free on contacting my email address. Fortunately, through prize money from national competitions, I have been able to set up websites and develop my ideas, but at times this can be a stressful and unpredictable way to get the necessary funding!

\section{Nigel Masters,}

Highfield Surgery, Highfield Way, Hazlemere, High Wycombe, Buckinghamshire, HP9 1TR. E-mail: nigel.masters@nhs.net

\section{REFERENCES}

1. Delaney B. General practice at the cutting edge of information technology, or failing to keep pace? $\mathrm{Br} J$ Gen Pract 2010; 60(573): 239-240.

2. Masters N. Learn about clinial indications. www.clinicalindications.com (accessed 11 May 2010).

3. Masters N, Tutt C. Smoking pack years. www.smokingpackyears.com (accessed 11 May 2010).

DOI: 10.3399/bjgp10X502245 